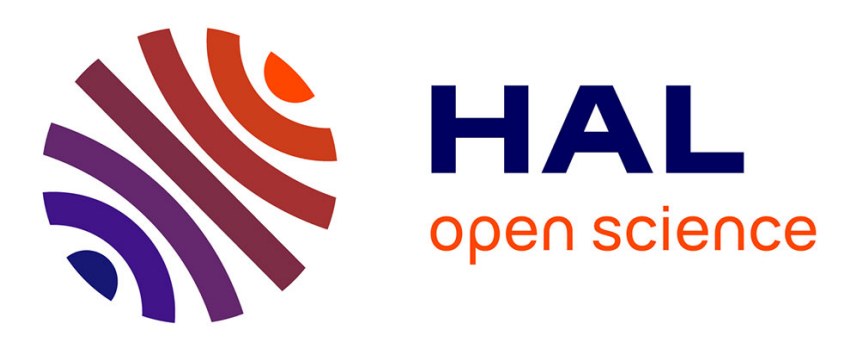

\title{
Morphology and Thermal Stability of Me-Si-N (Me=Re, W, Ta) for Microelectronics
}

\author{
A.-M. Dutron, E. Blanquet, V. Ghetta, R. Madar, C. Bernard
}

\section{To cite this version:}

A.-M. Dutron, E. Blanquet, V. Ghetta, R. Madar, C. Bernard. Morphology and Thermal Stability of Me-Si-N (Me=Re, W, Ta) for Microelectronics. Journal de Physique IV Proceedings, 1995, 05 (C5), pp.C5-1141-C5-1148. 10.1051/jphyscol:19955135 . jpa-00253832

\section{HAL Id: jpa-00253832 https://hal.science/jpa-00253832}

Submitted on 1 Jan 1995

HAL is a multi-disciplinary open access archive for the deposit and dissemination of scientific research documents, whether they are published or not. The documents may come from teaching and research institutions in France or abroad, or from public or private research centers.
L'archive ouverte pluridisciplinaire HAL, est destinée au dépôt et à la diffusion de documents scientifiques de niveau recherche, publiés ou non, émanant des établissements d'enseignement et de recherche français ou étrangers, des laboratoires publics ou privés. 


\title{
Morphology and Thermal Stability of Me-Si-N (Me=Re, W, Ta) for Microelectronics
}

\author{
A.-M. Dutron, E. Blanquet, V. Ghetta, R. Madar* and C. Bernard \\ INPG, ENSEEG, LTPCM, BP. 75, 38402 Saint-Martin-d'Hères, France \\ * INPG, ENSPG, LMPG, BP. 46, 38402 Saint-Martin-d'Hères, France
}

\begin{abstract}
Low pressure chemical vapor deposition (LPCVD) of $\mathrm{Me}-\mathrm{Si}-\mathrm{N}(\mathrm{Me}=\mathrm{Re}, \mathrm{W}$, Ta) thin films were investigated for use as diffusion barrier between $\mathrm{Cu}$ overlayer and oxidized silicon substrates. Their "amorphous" or nanocrystalline structure is expected to provide better performance than usual polycrystalline barriers. For the CVD process, gaseous precursors were silane, in situ fabricated metal chloride, ammonia, hydrogen and argon. Preliminary thermodynamic simulations of the Me-Si-N and the CVD Me-Si-N-Cl-H-Ar systems (Me=Re, W, Ta), were combined to the experimental study. The Re-Si-N and W-Si-N layers crystallization temperature was found to be around $1173 \mathrm{~K}$ after annealing in vacuum by Rapid Thermal Annealing. Their morphology, thermal stability and resistivity were evaluated as a function of annealing temperature.
\end{abstract}

\section{INTRODUCTION}

Amorphous ternary barriers against copper diffusion into silicon or $\mathrm{SiO}_{2}$ are now being investigated as an attractive alternative to polycrystalline counterparts. These new materials are usually composed of one metal, one non metal (Si or B) component and nitrogen such as Ta-Si-N [1-3], W-Si-N [4], W-B-N [5], Ti-Si-N [6,7]. Most of them were elaborated by Physical Vapor Deposition (PVD) and they were particularly studied for applications in microelectronics. Their very high crystallization temperature (around $1173 \mathrm{~K}$ ) is one of remarkable properties. Indeed, the lack of grain boundaries provides these materials with very good performance as diffusion barrier. For instance, different works showed that PVD Ti-Si-N barrier did not fail until $923 \mathrm{~K}$ [6] or $1123 \mathrm{~K}$ [7], PVD W-Si-N until $1073 \mathrm{~K}$ [4], and PVD Ta-Si-N until $1123 \mathrm{~K}[1-3]$.

The objective of this work is to compare the morphology and thermal stability (in terms of crystallization temperature and nature of the crystallized phases) of $\mathrm{Me}-\mathrm{Si}-\mathrm{N}(\mathrm{Me}=\mathrm{Re}, \mathrm{Ta}, \mathrm{W})$ thin films and establish a relationship between the stability of metal nitride $\mathrm{Me}-\mathrm{N}$ and the $\mathrm{Me}-\mathrm{Si}-\mathrm{N}$ thermal behavior. Low Pressure Chemical Vapor Deposition (LPCVD) technique was chosen since it is more and more attractive for 
submicron devices because of good step coverage and possible selectivity.

In this paper, the thermodynamic and experimental results for $\mathrm{Re}-\mathrm{Si}-\mathrm{N}$ are presented. The study on the Ta-Si-N and W-Si-N systems is now going on and preliminary results are reported.

For the elaboration of ternary alloys, gaseous precursors were : in situ fabricated metal chloride, silane and ammonia, diluted in hydrogen and argon.

$\mathrm{X}$-Ray Diffraction analysis was performed using a $\theta / 2 \theta$ detector with a fine monochromated Fe-K $\alpha$ beam, on as-deposited and annealed films. The films were observed by Transmission and Scanning Electron Microscopy (TEM and SEM), and their composition was determined by Rutherford Backscattering spectroscopy (RBS). Finally, the resistivity and the properties of $L P C V D \mathrm{Me}_{X} \mathrm{Si}_{y} \mathrm{~N}_{Z}(\mathrm{Me}=\mathrm{Re}, \mathrm{W})$ films are compared with films obtained with physical methods.

\section{THERMODYNAMICS}

The thermodynamic simulation, based on the minimization of the Gibbs free energy of the total Me-Si-N-H$\mathrm{Cl}$-Ar systems $(\mathrm{Me}=\mathrm{Re}, \mathrm{W}, \mathrm{Ta})$, was performed with Melange software [8] to provide the ternary phase diagrams and the nature of the phases present at equilibrium under the experimental chlorination and deposition conditions. Most of the data on the species generated in these systems came from the Scientific Group Thermodata Europe (SGTE) bank [9]. For the species not covered by this data bank, the data were critically selected from the literature available, particularly the data for rhenium silicides were taken from the work of J.S. Chen et al. [10], for the $\beta-S_{3} \mathrm{~N}_{4}$ from the work of P. Rocabois [11].The data for metal chlorides and silicides came from the studies of LPCVD ReSi2 [12], WSi2 [13] and TaSi2 [14]. Data for the metal nitrides $\mathrm{TaN}$ and $\mathrm{Ta}_{2} \mathrm{~N}$ were taken from Barin \& Knacke compilation [15]. To our knowledge, no $\mathrm{Re}-\mathrm{N}$ compound has been reported. In the case of $\mathrm{W}-\mathrm{N}$, there is very little experimental information. Some uncertainties on the existence at elevated temperatures (above $550 \mathrm{~K}$ ) of different nitrides were found in the literature [16-17]. Only one author proposed a complete calculated thermodynamic phase diagram [18]. First, we considered that in our investigated temperature (above $700 \mathrm{~K}$ ) and pressures (from 133 to $10^{5} \mathrm{~Pa}$ ) ranges, there are no stable tungsten nitrides. The ternary phase diagram $\mathrm{W}-\mathrm{Si}-\mathrm{N}$ established at $1000 \mathrm{~K}$ looks like the Re-Si-N diagram with three equilibria between $\mathrm{Si}_{3} \mathrm{~N}_{4}$ and $\mathrm{Me}, \mathrm{Me}_{5} \mathrm{Si}_{3}, \mathrm{MeSi}_{2}$ $(\mathrm{Me}=\mathrm{W}, \mathrm{Re})$. In the three $\mathrm{Me}-\mathrm{Si}-\mathrm{N}$ systems, as no ternary phase was reported in the literature, we assumed that no ternary phases exist. Similarly, we did not consider a thermodynamic description of any amorphous phases, eventhough amorphous films are expected to be deposited. We assumed that an amorphous material can be simulated as a mixture of crystalline compounds, for the same ternary composition. Ternary phase diagrams Re-Si-N (fig.1) and Ta-Si-N (fig.2) were calculated at different temperatures and pressures.On the other hand, the Ta-Si-N one is really different, with various equilibria: there is no $\mathrm{Si}_{3} \mathrm{~N}_{4}-\mathrm{Ta}$ equilibrium, the tantalum silicides are in equilibrium with TaN. On figure 2 is drawn the experimental domain of several studies of E. Kolawa et al. [1-3] who elaborated "amorphous" PVD Ta0.36 $\mathrm{Si}_{0.14} \mathrm{~N}_{0.50}$ films.

The thermodynamic simulation of rhenium, tungsten and tantalum chlorinations were carried out for the elaboration of $\mathrm{ReSi}_{2}[12] \mathrm{WSi}_{2}[13]$ and $\mathrm{TaSi}_{2}[14]$ thin films, respectively. 


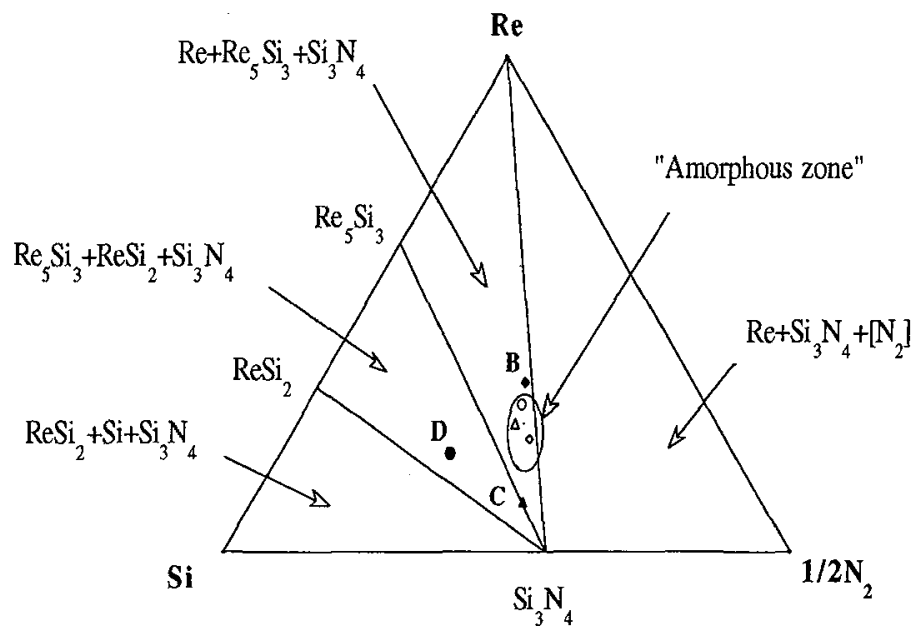

Figure 1: Ternary phase diagram Re-Si-N at $1073 \mathrm{~K}$ with simulated conditions (dot $\mathrm{B}, \mathrm{C}, \mathrm{D}$ ) and experimental compositions ("amorphous zone").

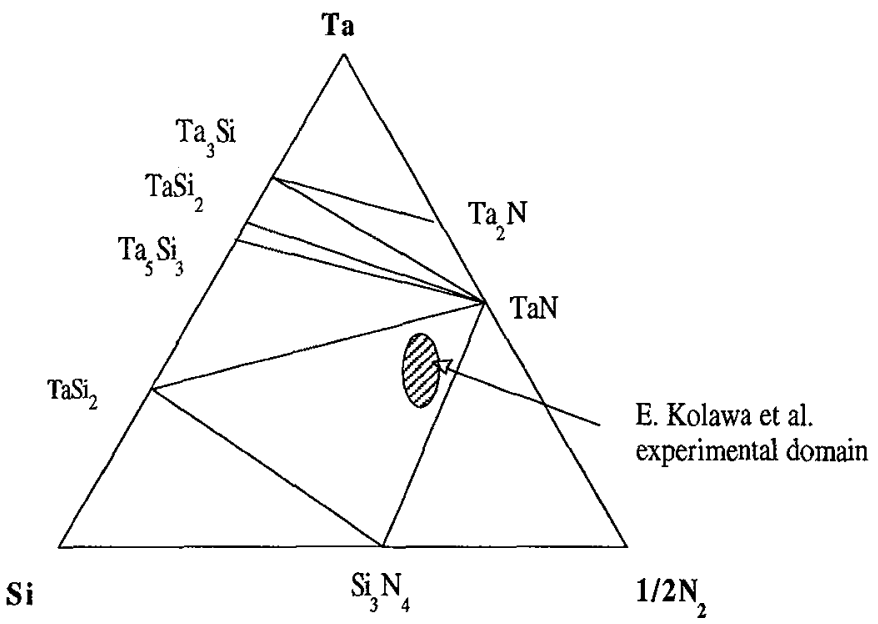

Figure 2: Ternary phase diagram Ta-Si-N established at $800 \mathrm{~K}$ with E. Kolawa et al. [1-3] experimental domain. 
The experimental rhenium and tantalum chlorination temperature and the total pressure were fixed to $823 \mathrm{~K}$ and to $1.197 * 10^{3} \mathrm{~Pa}$ (9 Torr). For tungsten chlorination, temperature and pressure were $1023 \mathrm{~K}$ and $0.665 * 10^{3} \mathrm{~Pa}$ (5 Torr), respectively. According to the thermodynamic results, for the above-mentionned experimental conditions, gaseous precursors $\mathrm{ReCl}_{5}(\mathrm{~g}), \mathrm{WCl}_{4}(\mathrm{~g})$, and $\mathrm{TaCl}_{4}(\mathrm{~g})+\mathrm{TaCl}_{5}(\mathrm{~g})$ were expected to be fabricated and transported [12-14]. In the case of the tungsten chlorination, this result was confirmed with a mass spectrometric investigation [13].

For the Re-Si-N system (fig.1), various phases could be obtained, but three different experimental points labeled B, C, D, which have been previously described [19], were retained. They correspond to the 3 domains : $\mathrm{Re}+\mathrm{Re}_{5} \mathrm{Si}_{3}+\mathrm{Si}_{3} \mathrm{~N}_{4}(\operatorname{dot} \mathrm{B}), \mathrm{Re}_{5} \mathrm{Si}_{3}+\mathrm{Si}_{3} \mathrm{~N}_{4}(\operatorname{dot} \mathrm{C}), \mathrm{Re}_{5} \mathrm{Si}_{3}+\mathrm{Si}_{3} \mathrm{~N}_{4}+\mathrm{ReSi} 2$ (dot D). For the elaboration of W-Si-N, the tested experimental condition was simulated in the $\mathrm{W}+\mathrm{Si}_{3} \mathrm{~N}_{4}+\mathrm{N}_{2}(\mathrm{~g})$ domain.

\section{EXPERIMENTAL}

In this paper, only results on $\mathrm{Re}-\mathrm{Si}-\mathrm{N}$ and $\mathrm{W}-\mathrm{Si}-\mathrm{N}$ films are presented. Ternary Me-Si-N films were elaborated in a vertical cold wall low pressure reactor described elsewhere [20]. The rhenium and tungsten chloride gaseous precursors were processed by in situ chlorination in the top section of the reactor. Rhenium pellets or tungsten wires were set up in a quartz tube and heated by a lamp furnace at respectively $823 \mathrm{~K}$ and $1073 \mathrm{~K}$, whereas chlorine passed through and formed $\mathrm{ReCl}_{5}(\mathrm{~g})$ or $\mathrm{WCl}_{4}(\mathrm{~g})$ [12-13]. Prior to deposition, the chlorination chamber was regenerated by heating the metallic charge at $823 \mathrm{~K}(\mathrm{Re})$ and $1073 \mathrm{~K}(\mathrm{~W})$ in a hydrogen reducing atmosphere during 15 to 30 minutes. This procedure was carried out to remove metal oxides and oxychlorides which may be present on the metal surface.

Layers were deposited on thermally oxidized $\langle 100\rangle$ oriented silicon (100nm $\mathrm{SiO}_{2}$ thickness). Deposition process was carried out at $1073 \mathrm{~K}$ for rhenium and $773 \mathrm{~K}$ for tungsten under a total pressure of $1.197 * 10^{3} \mathrm{~Pa}$ (9 Torr) and $0.665^{*} 10^{3} \mathrm{~Pa}$ (5 Torr), respectively. For the Re-Si-N and W-Si-N deposition, chlorine flow rate was fixed to 5 and $4 \mathrm{sccm} / \mathrm{min}$, hydrogen to 90 and $200 \mathrm{sccm} / \mathrm{min}$, diluted silane to 650 and $500 \mathrm{sccm} / \mathrm{min}$, respectively. Ammonia flow rate was varying from 2 to $10 \mathrm{sccm} / \mathrm{min}$ for Re-Si-N and was fixed to $30 \mathrm{sccm} / \mathrm{min}$ for $\mathrm{W}-\mathrm{Si}-\mathrm{N}$, in an argon atmosphere for a total flow rate of $11 / \mathrm{min}$. The as-deposited films were annealed in vacuum for 1 minute between 873 and $1273 \mathrm{~K}$ by rapid thermal annealing (RTA) in vacuum $\left(6.65 * 10^{-2} \mathrm{~Pa}\right)$.

\section{RESULTS AND DISCUSSION}

$\mathrm{X}$-Ray diffraction on as-deposited Re-Si-N films showed a nanocrystalline or amorphous morphology without any defined diffraction peak (curve a, fig. 3), whatever deposition conditions and substrate. After RTA in vaccum at $1173 \mathrm{~K}$, there was a Re crystallization in all the films (curve b). In the same way, there was a metal crystallization for tungsten (fig. 4).

In the case of PVD Ta-Si-N films, J.S. Reid et al.[4] mentionned that under vacuum annealing, the $\mathrm{Ta}_{0.36} \mathrm{Si}_{0.14} \mathrm{~N}_{0.50}$ films crystallized at $1373 \mathrm{~K}$ into $\mathrm{Ta}_{2} \mathrm{~N}, \mathrm{Ta} 5 \mathrm{Si}_{3}$ and "Ta4.5Si" and did not liberate nitrogen.

For the three tested conditions, RBS analysis gives an average composition of $\operatorname{Re}_{0.26} \mathrm{Si}_{0.34} \mathrm{~N}_{0.40}$ (located in the "amorphous zone" in fig. 1). Films may be composed with a mixture of $1 / 4 \mathrm{Re}+3 / 4$ non 
crystallized "Si $3 \mathrm{~N}_{4}$ ", with an excess of $\mathrm{Si}$ for all the selected points. After annealing, the overall composition did not change and no nitrgen out-gazing was evidenced under the uncertainties of RBS.

Transmission Electronic Microscopy (TEM) observation (fig. 5.a) showed on as-deposited Re-Si-N layer deposited on $\mathrm{Si} / \mathrm{SiO}_{2}(1000 \AA)$, that the ternary alloy appeared as a composite of very small particules identified as $\mathrm{Re}$ inserted in a non-crystallized " $\mathrm{Si}_{3} \mathrm{~N}_{4}$ " matrix.

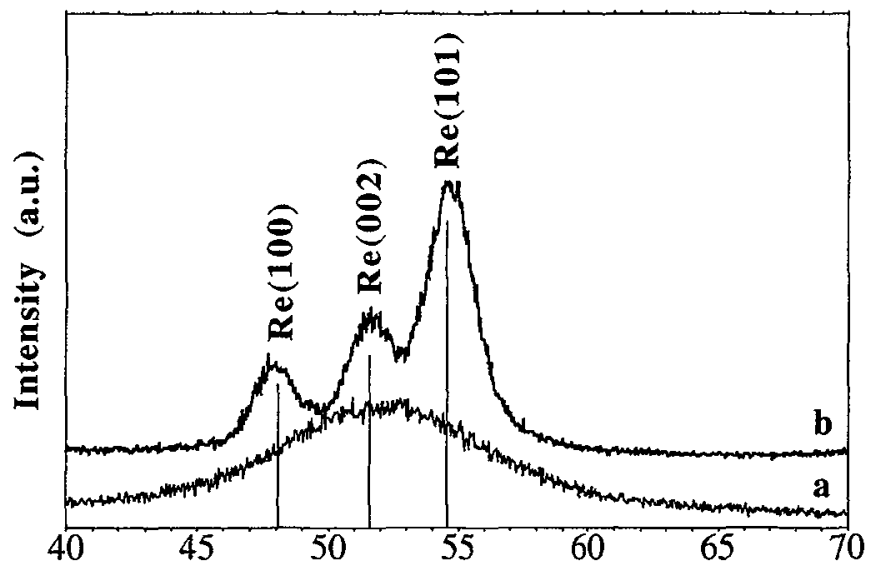

2 Theta

Figure 3: X-Ray Diffraction ( $\theta / 2 \theta$ scan detector mode, Fe-K $\alpha$ ) spectra on: as-deposited Re-Si-N film (a), and annealed film in vaccum at $1173 \mathrm{~K}(\mathbf{b})$.

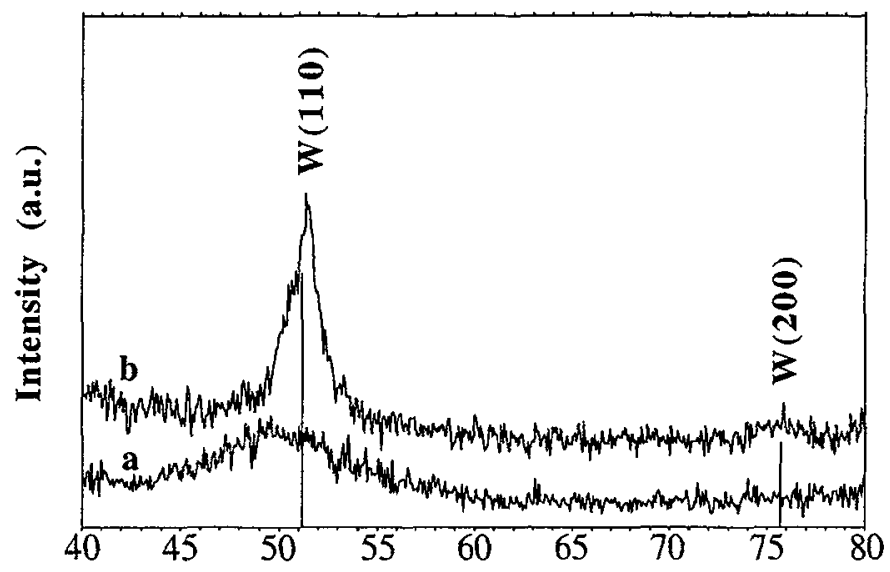

2 Theta

Figure 4: X-Ray Diffraction $(\theta / 2 \theta$ standart mod, Fe-K $\alpha$ ) spectra on: as-deposited W-Si-N film (a), film annealed in vaccum at $1173 \mathrm{~K}(\mathrm{~b})$ 
The average Re grain size was measured approximately to $15 \AA$. As revealed in fig.5.b, RTA at $1073 \mathrm{~K}$ in vacuum lead to grain growth since the average grain size reached then $50 \AA$. The material was now composed by spherical $\mathrm{Re}$ grains inserted in non-crystallized $\mathrm{Si}_{3} \mathrm{~N}_{4}$ (that will not crystallize until $1700 \mathrm{~K}$ [21]).

a

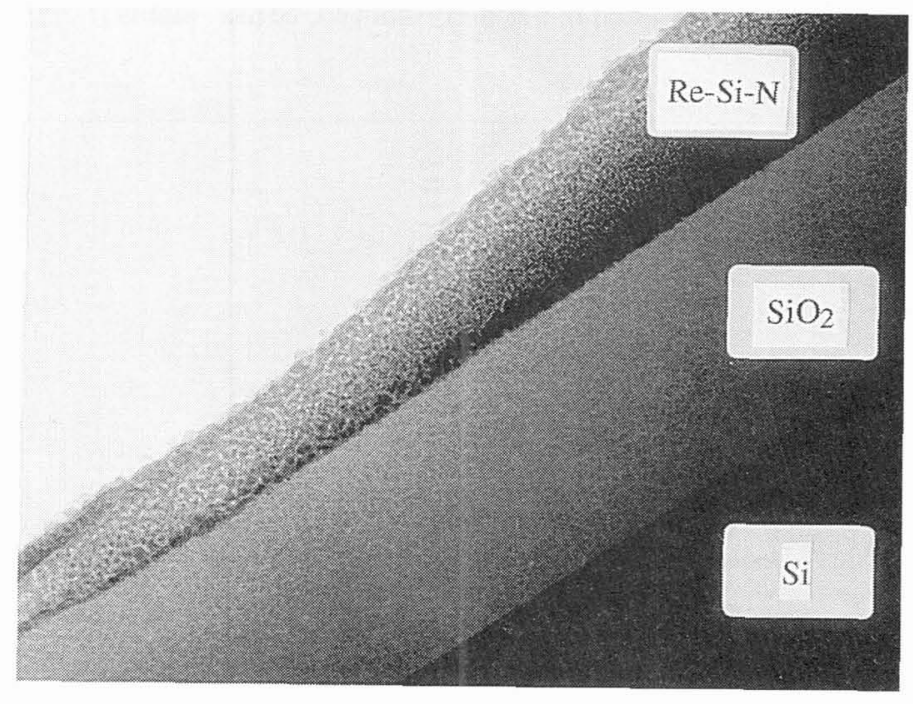

$300 \AA$

b

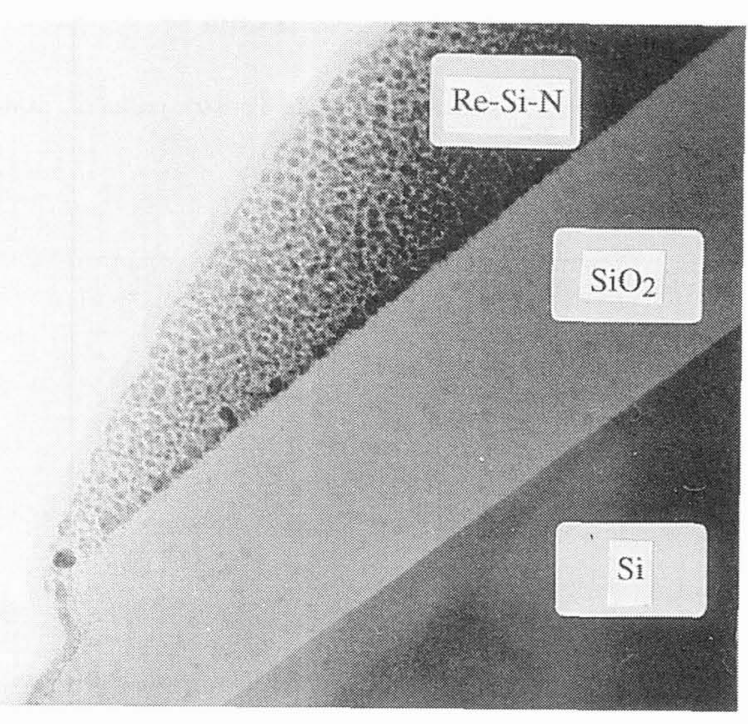

Figure 5: TEM pictures on cross-section of as-deposited Re-Si-N/SiO $2 / \mathrm{Si}$ (a), and $\mathrm{ReSi}-\mathrm{N} / \mathrm{SiO}_{2} / \mathrm{Si}$ after $\mathrm{RT}$ Annealing at $1073 \mathrm{~K}$

Resistivity was measured on as-deposited and annealed Re-Si-N (table 1) and W-Si-N films by the four point probes technique at room temperature. The resistivity of CVD Re-Si-N films increased with annealing temperature from 15 to $31 \mathrm{~m} \Omega \mathrm{cm}$ at $1073 \mathrm{~K}$ and after annealing at $1173 \mathrm{~K}$ measurement was not possible any more. Two explanations could be proposed: 
- an oxidation occurring with the annealing

- the increase of the distance between the rhenium particules (conductive phase) scattered in $\mathrm{Si}_{3} \mathrm{~N}_{4}$ (dielectric phase)

\begin{tabular}{|c|c|}
\cline { 2 - 2 } \multicolumn{1}{c|}{} & $\begin{array}{c}\text { Re-Si- } \mathrm{N} \text { film resistivity } \\
(\mathrm{m} \Omega \mathrm{cm})\end{array}$ \\
\hline as-deposited & 15 \\
\hline annealed at $873 \mathrm{~K}$ & 28 \\
\hline annealed at $1073 \mathrm{~K}$ & 31 \\
\hline annealed at $1173 \mathrm{~K}$ & - \\
\hline
\end{tabular}

Table 1: Resistivity of Re-Si-N films as a function of their thermal treatments.

The CVD W-Si-N layer resistivity value was found to be around $1.4 \mathrm{mWcm}$ which is comparable to the obtained value $(1.8 \mathrm{~m} \Omega \mathrm{cm})$ on PVD W-Si-N films [4]. The PVD Ta-Si-N thin films [1-3] resistivity was measured to $0.625 \mathrm{~m} \Omega \mathrm{cm}$.

To check the step coverage of LPCVD Me-Si-N layers, a Re-Si-N film was deposited on patterned substrate and was observed by SEM. Figure 6 represents a cross-section micrograph of the Re-Si-N film on $\mathrm{SiO}_{2}$ steps, and shows a step coverage ratio around 1 . That confirms that this CVD process is a promising technique for submicron devices.

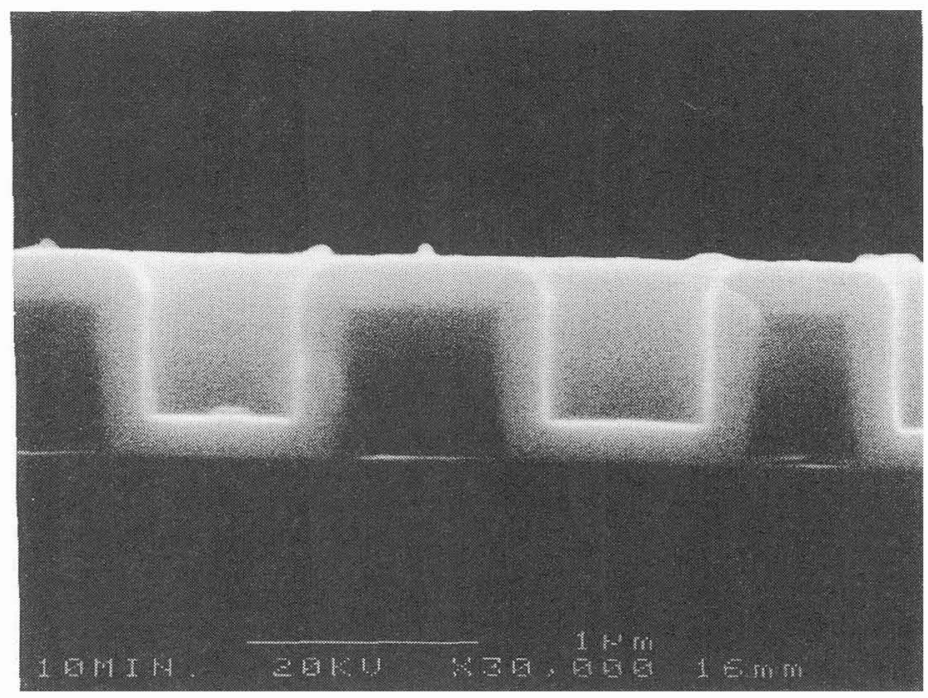

Figure 6 : Cross-section of a Re-Si-N film deposited over a patterned $\mathrm{SiO}_{2}$ substrate.

\section{CONCLUSION}

Morphology and thermal stability of ternary Me-Si-N thin films (Re, W, Ta), were investigated.

LPCVD Re-Si-N films, deposited on $\mathrm{SiO}_{2}$ at $1073 \mathrm{~K}$, were found to be composed of Re grains inserted in a non-crystallized $\mathrm{Si}_{3} \mathrm{~N}_{4}$ matrix. Annealing lead to $\mathrm{Re}$ grain growth and $\mathrm{Re}$ peaks were observed after annealing at $1073 \mathrm{~K}$ by X-Ray Diffraction. The first results on W-Si-N system indicated that it crystallized at $1173 \mathrm{~K}$ in the metal phase (W) such as the Re-Si-N system. PVD Ta-Si-N thin films fabricated by $\mathrm{E}$. 
Kolawa et al. [1-3] and J.S. Reid et al. [4] crystallized in tantalum silicides and tantalum nitrides at $1373 \mathrm{~K}$. The existence or non-existence of stable metal nitride could explain the differences observed in morphology and resistivity of these three systems.

\section{Acknowledgments:}

The author wish to thank J. Garden and J.P. Oberlin for their help in films analysis.

\section{References}

[1] E. Kolawa, J.S. Chen, J.S. Reid, P.J. Pokela, and M.-A. Nicolet, J. Appl. Phys. 70 (1991) 1369.

[2] E. Kolawa, P.J. Pokela, J.S. Reid, J.S. Chen and M.-A. Nicolet, Appl. Surf. Sci. 53 (1991) 373.

[3] E. Kolawa, J.S. Reid and J.S. Chen, Submicron Metallization, vol. 1805, SPIE, Bellingham WA (1992) 11.

[4] J.S. Reid, E. Kolawa, R.P. Ruiz and M.-A. Nicolet, Thin Solid Films 236 (1993) 319.

[5] S.Q. Wang, MRS Bulletin, Vol. XIX N8 (1994) pp30-40.

[6] T. Lijima, Y. Shimooka and K. Suguro, "Amorphous TiSiN barrier metal for Cu metallization", to be published.

[7] J.S Reid, X. Sun, E. Kolawa, and M.-A. Nicolet, IEEE Electron Device Letters, 15 (8) (1994) 298300

[8] J.N. Barbier and C. Bernard, "Melange software package", Proceedings of the 15th Calphad Meeting, ed. L.B. Kaufman, Calphad (1986) 206-212.

[9] Scientific Group Thermodata Europe, data bank, Domaine Universitaire B.P. 66, 38402 Saint-Martin d'Hères Cedex, France.

[10] J.S. Chen, E. Kolawa, M.-A. Nicolet, L. Baud, C. Jaussaud, R. Madar, C. Bernard, J. Appl. Phys., 75 (2) (1994) 897-901.

[11] P. Rocabois, Grenoble, France, Thesis (1993).

[12] A.-M. Dutron, E. Blanquet, N. Bourhila, R. Madar and C. Bernard, "A thermodynamic and experimental approach to ReSi2 LPCVD", accepted for publication in Thin Solid Films.

[13] N. Thomas, E. Blanquet, C. Vahlas,C. Bernard and R. Madar, Mat. Res. Soc. Symp. Proc., 204 (1991) 451-456.

[14] E. Blanquet, C. Vahlas, R. Madar, J. Palleau, J. Torres, and C. Bernard, Thin Solid Films 177 (1989) 189.

[15] I. Barin and O. Knacke, Thermochemical Properties of Inorganic Substances, Springer, Verlag, Berlin (1973).

[16] P.M. Hansen, Constitution of binary alloys, Ed. Mac Graw Hill (1958).

[17] H.A. Wriedt, Bulletin of Alloy Phase Diagrams Vol. $10 \mathrm{~N}^{\circ} 4$ (1989).

[18] A. F. Guillermetand S. Jonsson, Z. Metallkd. 84 (1993) 106-117.

[19] A.-M. Dutron, E. Blanquet, C. Bernard, A. Bachli, R. Madar, "LPCVD Re $\operatorname{Si}_{\mathrm{y}} \mathrm{N}_{\mathrm{z}}$ diffusion barriers in $\mathrm{Si} / \mathrm{SiO}_{2} / \mathrm{Cu}$ metallizations", to be published in Appl. Surf. Sc., Materials for Advanced Metallization '95, March 19-22, 1995, Radebeul, Germany.

[20] N. Thomas, P. Suryanarayana, E. Blanquet, C. Vahlas, R. Madar, and C. Bernard, J. Electrochem. Soc. 140, N.2, (February 1993).

[21] J.F. Lartigue, Grenoble, France, Thesis (1985). 